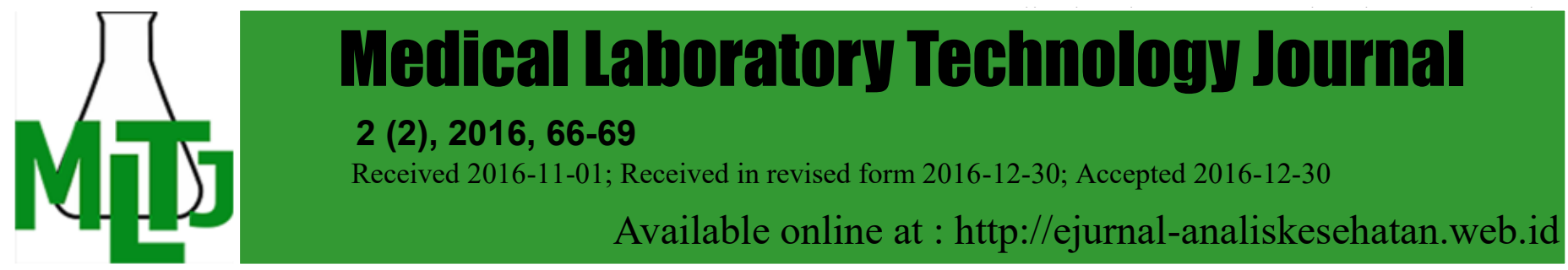

\title{
PERAN EKSTRAK DAUN PEPAYA (Carica papaya linn) TERHADAP KEMATIAN LARVA NYAMUK Aedes aegypti
}

\author{
Deby Swastika, Lenie Marlinae, Laily Khairiyati
}

\author{
Program Studi Kesehatan Masyarakat, Fakultas Kedokteran, Universitas Lambung Mangkurat. \\ jalan Akhmad Yani KM 35 Banjarbaru \\ e-mail: lailykhairiyati@unlam.ac.id
}

\begin{abstract}
Papaya plants contain many substances called papain, papain protease effect can kill larvae of Aedes aegypti. This study aimed to determine the effect of papaya leaves extracts (Carica papaya Linn) against Aedes aegypti larvae mortality. The research method was a quasi -experimental research design with Non-Equivalent Control Group. The concentration levels were $6.25 \%, 12.5 \%, 25 \%, 50 \%, 100 \%$, and controls (CMC-Na) with 4 times replication. The Probit Analysis test results showed Lethal concentration $\left(\mathrm{LC}_{50}\right)$ of papaya leaves extract (Carica papaya Linn) against Aedes aegypti larvae mortality was to $24.46 \%$ and the effective time is 22 hours. It is concluded that any different concentrations of papaya (Carica papaya Linn) leaves extract have effect on Aedes aegypti larvae mortality $(p<0.05)$, the time depth of papaya leaves extract have effect on Aedes aegypti larvae mortality $(p<0.05)$, the average number of Aedes aegypti larvae mortality for 24-hours in each concentration are concentration of $6.25 \%$ as much as 4.75 larvae, $12.5 \%$ concentration as much as 8 larvae, a concentration of $25 \%$ as much as 12 larvae, $50 \%$ concentration of 14.5 larvae, concentration $100 \%$ as much as 19 larvae and control as much as 1.25 larvae. The recommended suggestion is to conduct a phytochemical test to determine the active substances contained in papaya (Carica papaya Linn) leaves extract and to know the concentration of active substances in the extract.
\end{abstract}

Keywords: Papaya leaves extract; Aedes aegypti larvae

Abstrak: Tumbuhan Pepaya banyak mengandung zat yang disebut papain, efek protease papain dapat membunuh larva Aedes aegypti. Penelitian ini bertujuan mengetahui pengaruh ekstrak daun Pepaya (Carica papaya linn) terhadap kematian larva Aedes aegypti. Metode penelitian merupakan eksperimen semu dengan rancangan penelitian Non Equivalent Control Group. Tingkat konsentrasi adalah 6,25\%, 12,5\%, 25\%, 50\%, 100\% dan kontrol (CMC-Na) dengan 4 kali replikasi. Hasil uji Analisis Probit menunjukkan Lethal Consentration ( $\left.\mathrm{LC}_{50}\right)$ ekstrak daun Pepaya (Carica papaya linn) terhadap kematian larva Aedes aegypti sebesar $24,46 \%$ dan waktu efektif adalah 22 jam. Kesimpulan penelitian ini adalah berbagai konsentrasi ekstrak daun Pepaya (Carica papaya linn) berpengaruh terhadap kematian larva Aedes aegypti $(p<0,05)$, waktu pemberian ekstrak daun Pepaya (Carica papaya linn) berpengaruh terhadap kematian larva Aedes aegypti $(p<0,05)$, rata-rata jumlah kematian larva Aedes aegypti selama 24 jam konsentrasi 6,25\% sebanyak 4,75 larva, konsentrasi 12,5\% sebanyak 8 larva, konsentrasi 25\% sebanyak 12 larva, konsentrasi 50\% sebanyak 14,5 larva, konsentrasi $100 \%$ sebanyak 19 larva dan kontrol sebanyak 1,25 larva. Saran yang direkomendasikan adalah perlu dilakukan uji fitokimia untuk mengetahui zat aktif yang terkandung dalam ekstrak daun Pepaya (Carica papaya linn) dan mengetahui besar konsentrasi zat aktif dalam ekstrak tersebut.

Kata kunci: Ekstrak daun Pepaya; larva Aedes aegypti 


\section{PENDAHULUAN}

Masalah kesehatan telah menjadi kebutuhan pokok bagi masyarakat. Meningkatnya taraf hidup masyarakat, membuat tuntutan masyarakat terhadap mutu kesehatan juga meningkat (Wijaya LA., 2009). Tuntutan masyarakat terhadap mutu pelayanan juga telah dijamin oleh Menteri Kesehatan RI dalam peraturan Menteri Kesehatan RI nomor 741/MENKES/PER/VII/2008.

Menteri Kesehatan $\mathrm{Rl}$ akan menjamin mutu pelayanan kesehatan melalui monitoring dan evaluasi atas penerapan standar pelayanan minimal (SPM) kesehatan oleh pemerintah daerah (Fathi, Keman S dan Wahyuni GU., 2005).

Kasus DBD di Indonesia tahun 2010 menduduki peringkat 1 (satu) tertinggi di ASEAN sebanyak 150.000 kasus dengan jumlah kematian 1.317 jiwa, tahun 2011 menurun angkanya menjadi 49.868 kasus dan tahun 2012 kembali naik sebanyak 90.245 kasus. Kasus DBD di Kalimantan Selatan mengalami naik turun khususnya di Kota Banjarbaru selama 3 (tiga) tahun terakhir, yaitu pada tahun 2011 sebesar 12 kasus dengan satu kematian, pada tahun 2012 sebesar 213 kasus dengan dua kematian, dan pada tahun 2013 sebesar 182 kasus. Walaupun pada tahun 2013 tidak ada kematian, namun angka kasusnya tetap ditemukan (Dinkes kota Banjarbaru, 2013).

Tumbuhan Pepaya banyak mengandung zat atau unsur senyawa yang sering disebut papain (1 Wijaya LA., 2009). Papain adalah suatu zat (enzim) yang dapat diperoleh dari getah tumbuhan Pepaya dan buah Pepaya muda, sehingga mengandung enzim papain yang lebih tinggi pula terutama daun Pepaya yang masih muda (Wibisono E., 2010). Menurut Alboneh (2012), dalam penelitiannya menyebutkan bahwa zat pada daun Pepaya yang diduga memiliki potensi sebagai insektisida bagi nyamuk Aedes aegypti adalah enzim papain, saponin, flavonoid, dan tanin (Alboneh FH., 2012).

Kelebihan daun Pepaya adalah sangat populer, mudah diperoleh masyarakat, harganya relatif murah dan sering diolah menjadi jamu tradisional salah satunya masyarakat percaya rebusan air daun Pepaya sebagai obat penyakit DBD dan Malaria, serta sebagai keperluan dapur lainnya. Penggunaan larvasida alami dapat dilakukan untuk mengurangi resistensi larvasida kimiawi yang masih banyak digunakan masyarakat (Astuti, SD.,n.d). Berdasarkan hal tersebut, diperlukan penelitian tentang pengaruh ekstrak daun
Pepaya (Carica papaya linn) terhadap kematian larva Aedes aegypti.

Tujuan dari penelitian ini adalah untuk mengetahui pengaruh ekstrak daun Pepaya (Carica papaya linn) terhadap kematian larva Aedes aegypti.

\section{BAHAN DAN METODE}

Jenis penelitian ini adalah Eksperimental Semu untuk melihat pengaruh ekstrak daun Pepaya (Carica papaya linn) terhadap kematian larva Aedes aegypti. Rancangan penelitian yang digunakan adalah Non Equivalent Control Group. Bahan penelitian yang digunakan adalah larva Aedes aegypti instar IV. Bahan uji ekstrak daun Pepaya (Carica papaya linn) didapatkan dari hasil ekstraksi dengan etanol. Makanan untuk larva Aedes aegypti berupa air gula. Air yang digunakan adalah aquades untuk uji larvasida.

Pada penelitian ini menggunakan 1 kontrol dan 5 perlakuan, masing-masing perlakuan mengalami 4 kali replikasi. Variabel penelitian ini adalah variabel bebas, yaitu variasi konsentrasi ekstrak daun Pepaya (Carica papaya linn) dengan variasi $6,25 \%, 12,5 \%, 25 \%$, $50 \%$, dan $100 \%$ dan waktu pemberian ekstrak daun Pepaya (Carica papaya linn) selama 124 jam dan variabel terikat, yaitu kematian larva Aedes aegypti instar IV.

Data jumlah kematian larva Aedes aegypti dari keenam kelompok perlakuan diuji normalitas dan hasilnya menunjukkan bahwa data tidak berdistribusi normal, maka digunakan uji Kruskall-Wallis dengan derajat kepercayaan $95 \%$. Analisis dilanjutkan untuk melihat perbedaan dengan uji Mann-Whitney. Analisis untuk mengetahui $\mathrm{LC}_{50}$ ekstrak daun Pepaya (Carica papaya linn) dilakukan dengan menggunakan uji analisis Probit.

\section{HASIL DAN PEMBAHASAN \\ Pengaruh Berbagai Konsentrasi Ekstrak Daun Pepaya (Carica papaya linn) ter- hadap Kematian Larva Aedes aegypti}

Pengaruh berbagai konsentrasi $(6,25 \%$, $12,5 \%, 25 \%, 50 \%, 100 \%)$ ekstrak daun Pepaya (Carica papaya linn) terhadap kematian larva Aedes aegypti menunjukkan bahwa jumlah kematian larva pada berbagai tingkatan konsentrasi ekstrak daun Pepaya (Carica papaya linn) berbeda-beda, yaitu $6,25 \%, 12,5 \%, 25 \%, 50 \%, 100 \%$, dan kontrol, tergantung peningkatan konsentrasi ekstrak daun pepaya. Rata-rata jumlah kematian larva Aedes aegypti meningkat seiring dengan peningkatan pemberian konsentrasi ekstrak. 
Rata-rata peningkatan kematian larva pada setiap konsentrasi adalah $14,8 \%$ dan konsentrasi yang mampu mematikan $50 \%$ hewan coba yaitu larva Aedes aegypti adalah pada konsentrasi $25 \%$ sebanyak $60 \%$ kematian larva dari 20 larva Aedes aegypti.

\section{Jumlah Kematian Larva Aedes aegypti Selama 24 Jam dari Setiap Konsentrasi Ekstrak Daun Pepaya (Carica papaya linn).} Jumlah kematian larva Aedes aegypti selama 24 jam dari setiap konsentrasi ekstrak daun Pepaya (Carica papaya linn) menunjukkan bahwa rata-rata jumlah kematian larva Aedes aegypti selama 24 jam dari konsentrasi $6,25 \%$ sebanyak 4,75 ekor larva, dari konsentrasi $12,5 \%$ sebanyak 8 ekor larva, dari konsentrasi $25 \%$ sebanyak 12 ekor larva, dari konsentrasi $50 \%$ sebanyak 14,5 ekor larva, dari konsentrasi $100 \%$ sebanyak 19 ekor larva dan dari kontrol sebanyak 1,25 ekor larva. Penelitian ini menunjukkan bahwa ekstrak daun Pepaya (Carica papaya linn) dapat membunuh larva Aedes aegypti seperti yang dinyatakan oleh bahwa senyawa kimia yang terdapat pada Pepaya (Carica papaya linn) berpotensi membunuh larva Aedes aegypti (Farid, AM., 2015)

\section{Waktu Efektif Dalam 24 Jam Selama Pem- berian Ekstrak Daun Pepaya (Carica papa- ya linn) terhadap Kematian Larva Aedes aegypti}

Berdasarkan perhitungan uji lanjutan dengan menggunakan uji Mann-Whitney antara kelompok lama waktu pemberian selama 24 jam dengan kelompok lama waktu pemberian selama 1 jam sampai dengan 21 jam didapatkan nilai signifikansi kurang dari alpha $(\alpha=0,05)$, nilai ini menunjukkan terdapat perbedaan jumlah kematian larva antara antara kelompok lama waktu pemberian selama 24 jam dengan kelompok lama waktu pemberian selama 1 jam sampai dengan 21 jam. Sedangkan, hasil perhitungan uji uji MannWhitney antara kelompok lama waktu pemberian selama 24 jam dengan kelompok lama waktu pemberian selama 22 jam, dan 23 jam didapatkan nilai signifikansi lebihdari alpha $(\alpha=0,05)$, nilai ini menunjukkan tidak terdapat perbedaan jumlah kematian larva antara antara kelompok lama waktu pemberian selama 24 jam dengan kelompok lama waktu pemberian selama 22 jam, dan 23 jam. Oleh karena secara statistik diketahui bahwa lama waktu pemberian ekstrak daun Pepaya (Carica papaya linn) selama 22 jam, 23 jam dan 24 jam tidak terdapat perbedaan jumlah kematian larva, sehingga dapat disimpulkan bahwa waktu pemberian ekstrak selama 22 jam merupakan waktu efektif dengan jumlah kematian yang sama dengan waktu pemberian ekstrak selama 24 jam. Hal ini menunjukkan bahwa semakin lama waktu pemberian ekstrak daun Pepaya (Carica papaya linn) maka jumlah kematian larva akan semakin banyak. Waktu perlakuan akan menyebabkan mortalitas larva semakin tinggi. Hal ini terjadi karena toksisitas suatu insektisida ditentukan oleh 2 faktor yaitu dosage (dosis) dan duration (lama perlakuan) (Astuti, SD., 2014).

\section{Lethal Consentration $50 \quad\left(\mathrm{LC}_{50}\right)$ ekstrak daun Pepaya (Carica papaya linn) terhadap kematian larva Aedes aegypti}

Analisis untuk mengetahui Letal Consentration $\left(\mathrm{LC}_{50}\right)$ dapat diketahui melalui analisis Probit, yang bertujuan untuk mengetahui besarnya konsentrasi ekstrak daun Pepaya (Carica papaya linn) yang dapat membunuh larva nyamuk Aedes aegypti instar IV sebesar $50 \%$ dari populasi yang diuji. Hasil uji analisis Probit menunjukkan ekstrak daun Pepaya (Carica papaya linn) pada konsentrasi $24,456 \%$ dapat mengakibatkan kematian larva nyamuk Aedes aegypti instar IV sebesar $50 \%$ dari jumlah larva uji. Sehingga pada penelitian ini dapat diketahui bahwa ekstrak daun Pepaya (Carica papaya linn) yang efektif $\left(\mathrm{LC}_{50}\right)$ dalam membunuh larva nyamuk $A e-$ des aegypti instar IV adalah sebesar $24,456 \%$. Hasil penelitian ini berbeda dengan penelitian Shadana M. dkk., yang menyatakan konsentrasi ekstrak etanol daun pepaya yang dapat membunuh $50 \%$ dari populasi larva Ae.aegypti $\left(\mathrm{LC}_{50}\right)$ dalam rentang waktu 24 jam sebesar 945,165 ppm (Shadana M., dkk., 2014).

Bahan aktif yang dimiliki daun papaya adalah enzim papain, alkaloid karpain, pseudo-karpain, glikosid, karposid, saponin, flavonoid, , dekstrosa levulosa dan sakarosa. Bahan aktif dengan potensi sebagai insektisida adalah enzim papain, saponin, flavonoid dan alkaloid karpain. Senyawa-senyawa tersebut menimbulkan berbagai reaksi kimia dalam tubuh larva dan menyebabkan terganggunya pertumbuhan dan perkembangan larva (Utomo, M, Amaliah, S, Suryati, Febria A., 2010). 


\section{KESIMPULAN}

Berbagai konsentrasi ekstrak daun Pepaya (Carica papaya linn) berpengaruh terhadap kematian larva Aedes aegypti $(p<0,05)$, waktu pemberian ekstrak daun Pepaya (Carica papaya linn) berpengaruh terhadap kematian larva Aedes aegypti $(p<0,05)$, rata-rata jumlah kematian larva Aedes aegypti selama 24 jam konsentrasi $6,25 \%$ sebanyak 4,75 larva, konsentrasi $12,5 \%$ sebanyak 8 larva, konsentrasi 25\% sebanyak 12 larva, konsentrasi 50\% sebanyak 14,5 larva, konsentrasi 100\% sebanyak 19 larva dan kontrol sebanyak 1,25 larva.

\section{SARAN}

Perlu dilakukan uji fitokimia untuk mengetahui zat aktif yang terkandung dalam ekstrak daun Pepaya (Carica papaya linn) dan mengetahui besar konsentrasi zat aktif dalam ekstrak tersebut.

\section{DAFTAR PUSTAKA}

Adityo, M. F. (2015). Effectivity Of Papaya Leaves (Carica papaya I) as Inhibitor of Aedes aegypti Larvae. J MAJORITY, 4(5), $1-4$.

Alboneh, F. (2012). Uji potensi ekstrak etanol daun pepaya (Carica papaya) sebagai insektisida terhadap nyamuk Aedes Sp dengan metode elektrik. Program Studi Pendidikan Dokter Fakultas kedokteran Universitas Brawijaya Malang.

Astuti, S. D. (n.d.). Efek ekstrak etanol 70\% daun pepaya (Carica papaya, Linn.) terhadap aktivitas AST dan ALT pada tikus galur wistar setelah pemberian obat tuberkulosis (Isoniazid \& Rifampisin). surakarta.

Fathi, Keman, S., \& Wahyuni, G. U. (2005). Peran faktor lingkungan dan perilaku terhadap penularan demam berdarah dengue di Kota Mataram. Jurnal Kesehatan Lingkungan, 2(1), 1-10.

Meidy, S., Suri, D. L., \& Yulis Hamidy, M. (2014). Efek Larvasida Ekstrak Etanol Daun Pepaya(Carica papaya) Terhadap Larva Aedes aegypti. Fakultas Kedokteran Universitas Riau.

Rekapitulasi Jumlah Kasus DBD Di Kota Banjarbaru Tahun 2013. (2013). Banjarbaru: Dinas Kesehatan Kota Banjarbaru.

Tyas, D. W., Wahyuni, D., \& Hariyadi, S. (2014). Perbedaan toksisitas ekstrak, rebusan dan rendaman daun Pepaya (Carica papaya linn) terhadap mortalitas larva nyamuk Aedes aegypti. L. Pancaran, 3(1), 59-68.
Utomo, Amaliah, M., Suryati, S., \& Febria, A. (2010). Daya Bunuh Bahan Nabati Serbuk Biji Papaya Terhadap Kematian Larva Aedes aegypti Isolat Laboratorium B2P2VRP Salatiga. In Prosiding Seminar Nasional UNIMUS.

Wibisono, E. (2010). Imobilisasi crude enzim papain yang diisolasi dari getah buah pepaya (Carica papaya L) dengan menggunakan kappa karagenan dan kitosan serta pengujian aktivitas dan stabilitasnya. Universitas Sumatera Utara Medan.

Wijaya, L. A. (2009). Daya bunuh ekstrak biji kecubung (Datura metel) terhadap larva Aedes aegypti. Fakultas Kedokteran Universitas Sebelas Maret. 